\section{ANNUAL MEETING SUMMARY}

The 1979 Annual Meeting at the Hyatt Regency Hotel in Boston was eminently successful, drawing 944 registrants. The Von Hippel Award was presented to Professor David Turnbull of Harvard University for his outstanding contributions to Materials Science.

The total number of symposia was 13. Some of the larger symposia, such as Scientific Basis for Nuclear Waste Management and Laser and Electron Beam Processing of Materials, are now clearly recognized as the premier international meetings in these disciplines. The smaller symposia were well attended and reflect the Society's ability to sponsor and develop important emerging areas of Materials Science. Chairpersons and organizers are to be congratulated for an outstanding meeting.

\section{ACCEPTANCE REMARKS FOR THE VON HIPPEL AWARD OF THE MATERIALS RESEARCH SOCIETY, HYATT REGENCY HOTEL, BOSTON, MASSACHUSETTS - NOVEMBER 27, 1979}

\section{SOME THOUGHTS ON DIRECTIONS IN MATERIALS SCIENCE}

\section{David Turnbull,* Division of Applied Sciences, Harvard University}

It is a high honor to receive this award; especially so, considering the distinction of the first two recipients: Professor von Hippel, who pioneered brilliantly in the development and definition of Materials Science, and Dr. Baker, under whose leadership were made the great scientific and technological discoveries at Bell Laboratories during the past decades. It is not clear to me that I belong in this progression. I feel

\footnotetext{
* Since 1962 Dr. Turnbull has been Gordon McKay Professor of Applied Physics at Harvard University, coming to Harvard from General Electric Research Labs, Schenectady, N. Y.
}

that I am in a position rather like that of a certain Linus. I'm sure that you all know of two famous persons named Linus but you may not have heard of the Linus to whom I refer. He was identified by the ecclesiastical historian Eusebius as the first Bishop of Rome following the Apostles Peter and Paul. In any event, this award indicates that some of my colleagues, rightly or wrongly, think highly of me and that is pleasant to know.

When Ken Jackson told me of the award he said that on the occasion of it I should present a talk. I thought that I might base the talk on the research of my associates and myself on the mechanism of crystal growth in covalent systems. However, Ken tactfully informed me that so technical a topic would not be quite appropriate. Instead, I should attempt something rather more cosmic or, at least, amusing. What follows will be some highly personal, and rather disjointed views on where Materials Science is, how it got where it is and where it may be going.

It seems logical that Materials Science begin where conventional Chemistry ends. That is, it would be the science of characterizing, synthesizing and explaining ultramolecular structures. Such a definition is tidy for a dictionary but it is, perhaps, overly inclusive in that it intrudes on a number of already well developed and organized disciplines. More realistically, Materials Science is the science of the more complex features of the structure and behavior of real solids; especially those features which depend critically on the various structural imperfections - surfaces, internal boundaries, point and line defects sometimes in thermodynamic equilibrium but more often in configurationally frozen states. The especial forte of the Materials Scientist is in determining the basic components of complex structures, how they act to produce the structures' responses to applied forces and thermal treatments and in synthesizing new materials which may exhibit unique responses.

Indeed, the main preoccupations in solid state science have, I think, progressed 